\title{
Regulation of cytokine production during phagocytosis of apoptotic cells
}

\author{
Elaine Y Chung ${ }^{1}$, Sun Jung Kim², Xiao Jing $\mathrm{Ma}^{1}$ \\ ${ }^{1}$ Department of Microbiology and Immunology, Weill Medical College of Cornell University, 1300 York Avenue, New York, NY 10021, \\ USA; ${ }^{2}$ Department of Medicine, Columbia University, New York, NY 10027, USA
}

Loss of self-tolerance and expansion of auto-reactive lymphocytes are the basis for autoimmunity. Apoptosis and the rapid clearance of apoptotic cells by phagocytes usually occur as coordinated processes that ensure regulated cellularity and stress response with non-pathological outcomes. Defects in clearance of apoptotic cells would contribute to the generation of self-reactive lymphocytes, which drive autoimmune disorders such as rheumatoid arthritis (RA) and systemic lupus erythematosus (SLE). The IL-12 family of cytokines (IL-12, IL-23, and IL-27) and IL-10 are produced by phagocytic macrophages and play critical roles in the regulation of antigen-presenting cells (APCs) and effector lymphocytes during an immune response to pathogens. Inappropriate expression of these cytokines and their dysregulated activities have been strongly implicated in the pathogenesis of several autoimmune diseases. The production of pro- and anti-inflammatory cytokines by phagocytic APCs is delicately regulated during the ingestion of apoptotic cells as part of an intrinsic mechanism to prevent inflammatory autoimmune reactions. How apoptotic cell-derived signals regulate cytokine production is poorly understood. A recent study by our group demonstrated that phagocytosis of apoptotic cells by activated macrophages results in strong inhibition of IL-12 p35 gene expression by activating a novel transcription repressor, which we named GC-binding protein (GC-BP), through tyrosine dephosphorylation. We are also beginning to understand the molecular mechanisms underlying apoptotic cell-triggered production of IL-10 by phagocytes. These studies will help to elucidate some novel immune regulatory mechanisms and explore the regulation of immune responses to autoantigens with potentials to discover new therapeutic targets for the treatment of autoimmune disorders.

Cell Research (2006) 16:154-161. doi:10.1038/sj.cr.7310021; published online 13 February 2006

Keywords: cytokines, apoptotic cells, phagocytosis, autoimmunity

\section{Clearance of apoptotic cells by professional phago- cytes}

Multicellular organisms have evolved genetic and epigenetic mechanisms of programmed cell death (apoptosis) to eliminate cells that are no longer needed or damaged. Physiological apoptosis has an essential role in development, differentiation and tissue homeostasis [1]. The elimination of apoptotic cells and cell bodies by phagocytes represents an evolutionarily conserved means to prevent exposure of surrounding tissue to potentially cytotoxic,

Correspondence: Xiao Jing Ma

Tel: 212-746-4404; Fax: 212-746-4427;

Email: xim2002@med.cornell.edu. immunogenic, or inflammatory cellular contents $[2,3]$. When apoptosis occurs at moderate rates such as during normal adult tissue turnover, neighboring cells such as fibroblasts can act as phagocytes in their ingestion and clearance. When apoptosis occurs on large scales such as during embryonic morphorgenesis, ionizing radiation, and acute infections, macrophages are the major professional phagocytes that play important roles in the clearance of apoptotic cells. Macrophages are attracted to sites of high rate of apoptosis such as the thymus and the follicles of secondary lymphoid tissues in the immune system.

\section{Phagocytic receptors and apoptotic cell ligands}

Apoptotic cells exhibit numerous changes including 
alteration of membrane lipid molecules and carbohydrates. There are four major phospholipids in the plasma membrane of many mammalian cells, phosphatidylcholine (PC), phosphatidylethanolamine (PE), phosphatidylserine (PS) and sphingomyelin. PS is normally limited to the inner layer of the lipid bilayer [4] but is found at higher levels on the outer leaflet of cell membranes that are undergoing apoptosis due to a poorly understood inhibition of an aminophospholipid translocase [5] and the activation of a lipid scramblase [6]. The observation that apoptotic cells that do not express PS are poorly phagocytosed suggests that PS provides an important signal in the recognition and/or clearance of apoptotic cells [7]. The process of removing dead cells is carried out by a wide variety of cell types and involves multiple receptors [8], such as scavenger receptors, oxidized low-density lipoprotein receptors, CD14, CD68, CD36, and vitronectin receptor, and apoptotic cell ligands. The exposed PS on apoptotic cells is recognized by several phagocyte receptors including a presumptive phosphatidylserine (PS) receptor (PSR) [9]. Ligation of this presumptive PSR has been proposed to be the primary mechanism through which these responses are initiated [10], although experimental demonstration of such a receptor has been quite controversial [11].

A 4-step process has been proposed to account for the recognition and ingestion of apoptotic cells by phagocytes. Ligation of the "PSR" on phagocytes delivers a "tickle" signal, which stimulates the internalization of apoptotic cells, including bystander cells, that are "tethered" to the phagocytes through other recognition receptors. Simultaneously, the immune response is modulated through secretion of immunosuppressive cytokines [12].

\section{Phagocytosis of apoptotic cells and regulation of im- mune responses}

Resolution of inflammation depends not only on the removal of apoptotic cells but also on active suppression of inflammatory mediator production. Aberrations in either mechanism are associated with chronic inflammatory conditions and autoimmune disorders [13-15]. Uptake of apoptotic cells by phagocytes is thought to suppress autoimmune responses through the release of anti-inflammatory cytokines IL-10, TGF- $\beta$, platelet activating factor (PAF), and prostaglandin $\mathrm{E}_{2}\left(\mathrm{PGE}_{2}\right)$, and inhibition of proinflammatory cytokines TNF- $\alpha$, GM-CSF, IL-12, IL-1 $\beta$, and IL-18 [16-18].

In human systemic lupus erythematosis (SLE), impaired phagocytosis of apoptotic materials by macrophages has been reported $[19,20]$, providing an explanation for increased levels of early apoptotic cells, DNA, and nucleosomes observed in the circulation of SLE patients [21-24].
The impaired clearance of apoptotic cells resulting in an accumulation of late apoptotic and secondary necrotic cells including oligosomes might lead to an activation of autoreactive $\mathrm{T}$ and $\mathrm{B}$ cells [16].

\section{IL-12 family of cytokines in autoimmunity}

IL-12 is an important cytokine in both the innate and adaptive phases of host immune defenses against intracellular pathogens. IL-12 is a heterodimer produced primarily by macrophages and DCs. It is a key factor in the induction of $\mathrm{T}$ cell-dependent and independent activation of macrophages, NK cells, generation of T helper type 1 (Th1) cells and CTL, induction of opsonizing, complement-fixing antibodies, and resistance to intracellular infections [25]. The genes encoding the two heterologous chains of IL-12, p40 and p35 are located on different human and mouse chromosomes. Together, $\mathrm{p} 40$ and p35 form the biologically active IL-12 (also called p70). The p 40 chain is also shared with another IL-12-related cytokine, IL-23, which is composed of p40 and an IL-12-independent subunit p19 [26]. The highly coordinated expression of p40 and p35 genes to form IL-12 p70 in the same cell type at the same time is essential for the initiation of an effective immune response. IL-12 is also an important player in Tcell-mediated autoimmunity $[27,28]$. Specifically, IL-12 administration exacerbates autoimmune phenomena by inducing the differentiation of Th1 autoreactive cells [29, 30] whereas the lack of IL-12/IL-23 p40 in genetically deficient mice or mice treated with anti-IL-12 antibody abrogated diseases in experimental models of autoimmunity such as insulin-dependent diabetes mellitus (IDDM) in NOD mice [31,32], experimental allergic encephalomyelitis (EAE) [33, 34], experimental autoimmune uveitis (EAU) [35, 36], and collagen-induced arthritis (CIA) [37]. Aberrant levels of IL-12 are produced by macrophages isolated from young mice prone to lupus (MRL and NZB/W) [38]. The diabetes-associated quantitative trait locus, Idd4, was found to be responsible for the IL-12 p40 overexpression in nonobese diabetic (NOD) mice.[39] Administration of IL-12 to aging mice renders them vulnerable to the induction of experimental SLE induced by the monoclonal anti-DNA autoantibody bearing the 16/6Id.[40] In human patients with SLE, elevated levels of IL-12, IL-18 is observed [41-43], and the higher serum IL-12 levels are correlated with fever in subjects but not with renal diseases [44]. Moreover, PBMCs from patients with active SLE were found to be more sensitive to IL-12 by inducing phosphorylation of STAT3 and STAT4 [45]. IL-12 produced by DCs in a CD $4^{+} \mathrm{T}$ cell-dependent manner is able to break tolerance and activates $\mathrm{CD} 8^{+} \mathrm{T}$ cell effector functions in graft rejection [46]. Administration 
of IL-12 and IL-18 in vivo can break oral tolerance to ovalbumin with abrogated suppression of specific IgG2a production, delayed-type hypersensitivity responses and IFN- $\gamma$ production by antigen-specific T cells [47].

IL-27 is the latest addition to the IL-12 family. IL-27 is a heterodimeric protein consisted of Epstein-Barr virus (EBV)-induced gene 3 (EBI3), a p40-related protein, and p28, a newly discovered IL-12 p35-related polypeptide. IL-27 appears to be produced early by activated antigenpresenting cells. It is able to induce clonal proliferation of naïve but not memory $\mathrm{CD} 4^{+} \mathrm{T}$ cells and synergizes with IL-12 in IFN- $\gamma$ production by naïve $\mathrm{CD}^{+} \mathrm{T}$ cells [48]. Recently, an orphan receptor was described with $26 \%$ homology and $37 \%$ similarity to the IL- $12 \mathrm{R} \beta 2$ subunit and to gp130, respectively, designated TCCR [49] or WSX-1 [50]. This receptor was identified as one of the receptor subunits for IL-27 and is necessary but not sufficient for IL-27 function [48]. It has been suggested that IL-27 and IL-12 function sequentially in initiating and maintaining Th1 responses, respectively [48, 50]. Recombinant IL-27 expressed from tumor cells has been shown to elicit potent tumor-specific immune responses in vivo and result in complete regression of orthotopic primary and metastatic murine neuroblastoma tumors [51], and Colon 26 murine colon carcinoma [52].

Li et al, reported that IL-27 p28 and EBI3 subunits and WSX-1 mRNAs were markedly upregulated in inflammatory cells in the CNS during EAE [53]. Furthermore, neutralizing the in vivo function of IL-27 by antibodies against IL-27 p28 rapidly suppressed an ongoing long-lasting disease in C57BL/6 mice [54]. These studies strongly suggest the involvement of IL-27 in autoimmunity.

\section{Mechanisms of apoptotic cell-induced inhibition of IL-12 production}

Phagocytosis of apoptotic cells usually results in an anti-inflammatory state with an inhibition of proinflammatory cytokines such as IL-12. How apoptotic cell-derived signals regulate IL-12 gene expression was not understood. We demonstrated recently [55] that cell-cell contact with apoptotic cells is sufficient to induce profound inhibition of IL-12 production by activated macrophages. PS could mimic the inhibitory effect. The inhibition does not involve autocrine or paracrine actions of IL-10 and TGF- $\beta$. Moreover, we reported the identification, purification and cloning of a novel zinc finger-like nuclear factor, named GC-binding protein (GC-BP), that is induced following phagocytosis of apoptotic cells by macrophages or by treatment with PS. GC-BP selectively inhibits IL-12 p35 gene transcription by binding to its promoter in vitro and in vivo, thus decreasing IL-12 production. Blocking GC-
BP by RNA interference restores IL-12 p35 transcription and IL-12 p70 synthesis. Upon contact with apoptotic cells, GC-BP, which is present in both the cytoplasm and nucleus, undergoes dephosphorylation possibly at tyrosine 15. The tyrosine-dephosphorylated GC-BP binds the IL12 p35 gene promoter between +13 and +19 , and blocks its transcription, thereby inhibiting IL-12 production [55]. The reduced capacity of macrophages to produce IL-12 is associated with an impaired ability to promote IFN- $\gamma$ production by activated $T$ cells [56].

\section{GC-binding protein (GC-BP)}

The GC-BP gene is uniquely present in the mouse genome, located on chromosome 7 , with a postulated 3 -exon structure spanning $\sim 10 \mathrm{~kb}$. The 615 -amino acid residues of GC-BP with a calculated molecular weight of $68.3 \mathrm{kDa}$ predict strongly that it is a zinc finger-containing protein and transcriptional repressor. The mouse cDNA was originally isolated from a tissue biopsy of the MMTV-LTR/INT3 mammary tumor. PSORT II analysis indicates with a very high probability and reliability $(>95 \%)$ that it is a nuclear protein with 16 putative $\mathrm{C} 2 \mathrm{H} 2$ type zinc finger motifs that could interact with DNA. However, in reality it is present in approximately equal amounts in the cytoplasm and in the nucleus, and the importance of these putative zinc fingers is uncertain since the $\mathrm{N}$-terminal 27 amino acids with only one zinc finger retains $\sim 50 \%$ of GC-BP's transcriptional capacity [55]. There is a human ortholog of the predicted protein sequence of mouse GC-BP: hypothetical protein FLJ13479 (NCBI database), which is $93 \%$ homologous to its mouse counterpart. Mouse GC-BP shares 33\% homology with mouse zinc finger protein 51(Zfp-51), with 19 contiguous zinc fingers and being ubiquitously expressed [57]. The rat homologue of GC-BP ( $40 \%$ at amino acid level) is zinc finger protein 37 (Zfp-37), a novel peroxisome proliferator responsive cDNA isolated originally from rat hepatocytes [58]. In this context, it is curious to note that there is a good putative binding site, AGGTCT, in the 5' UTR of GC-BP for peroxisome proliferator-activated receptor (PPAR)/retinoid X receptor (RXR) heterodimers. PPARs as well as another family of nuclear hormone receptors, liver X receptors (LXRs), are activated by trigleride-rich lipoproteins, oxidized low-density lipoprotein (LDL), and apoptotic cells in macrophage lipid metabolism [59]. Relevantly, it has been shown that PPAR $\gamma$ agonists can inhibit experimental autoimmune encephalomyelitis (EAE), a Th1 cell-mediated inflammatory demyelinating disease model of multiple sclerosis (MS), by blocking IL-12 production, IL-12 signaling and Th1 differentiation [60]. Thus, GCBP may have additional unidentified targets involved in broader areas of biology than the original data revealed. 


\section{Model of GC-BP-mediated inhibition of IL-12 pro- duction during phagocytosis}

Apoptotic cells, upon contact with professional phagocytes induce a profound inhibition of IL-12 production, in part, by selectively targeting the transcription of the p35 gene. The chief findings of our recently published study $[55,61]$ and our working hypothesis are summarized as follows:

1) A target cell undergoing apoptosis displays characteristic surface changes including externalization of PS, which serves as a marker recognized by phagocytes such as macrophages.

2) The interaction between the apoptotic cell and the macrophage, particularly between PS and PSR, initiates a signaling event that acts on the GC-BP.

3) Dephosphorylation of GC-BP on tyrosine 15 occurs.

4) The dephosphorylated GC-BP binds to the GC-element in the IL-12 p35 promoter.

5) The binding of GC-BP prevents IL-12 p35 gene transcription, thus IL-12 protein synthesis.

6) In the meantime, the interaction between the apoptotic cell and the macrophage including the PS-PSR interaction results in the production of anti-inflammatory cytokines such as TGF- $\beta$ ? and IL- 10 .

7) Together, the suppression of pro-inflammatory cytokines such as IL-12 and anti-inflammatory cytokines prevent $\mathrm{T}$ cell activation and induce tolerance.

\section{Role of IL-10 in homeostatic regulation of inflamma- tion and immune response}

IL-10 is a pleiotropic cytokine produced by both T and B cells and macrophages and possesses both anti-inflammatory and immunosuppressive properties [62]. The ability of IL-10 to inhibit cytokine production by both T cells and NK cells was found to be indirect, via inhibition of accessory cell (monocyte/macrophage) function [63-66]. These initial studies were soon followed by extensive research showing that IL-10 is an inhibitor of a broad spectrum of monocyte/macrophage functions, including cytokine synthesis, nitric oxide production, and expression of MHC class II and costimulatory molecules such as CD80/CD86 [67-74]. Investigations in numerous inflammatory disease models including chronic enterocolitis, cutaneous inflammatory condition, endotoxic shock and Shwartzman reaction, and autoimmune encephalomyelitis in IL-10-deficient mice have yielded strong evidence that IL-10 plays a central role in vivo in restricting inflammatory responses [75-79]. However, endogenous IL-10 production and systemic administration can also exacerbate macrophage- and T-cell dysfunction, decrease T-cell apoptosis, blunt antimicrobial activity, and increase mortality in other less acute bacterial models of sepsis or after thermal injury [80]. In addition, IL-10 also processes immunostimulatory effects that have not attracted sufficient attention. IL-10 is a potent growth factor for B lymphocytes. It promotes B cell proliferation, antibody production, and class II expression [81]. IL-10 enhances, paradoxically, the development of cytotoxic $\mathrm{T}$ lymphocytes (CTL) [82-84]. It induces NK cytotoxicity against NK-resistant tumor cells in vitro and increases IL2-induced NK cell proliferation [85]. It acts as a co-factor for colony formation by mast cell progenitors [86] and thymocytes [87]. The B cell-stimulating property of IL-10 is thought to be the basis of several antibody-mediated autoimmune disorders [88].

\section{IL-10 gene expression in microbe- and cytokine-ac- tivated macrophages}

A key feature of macrophages is their ability to produce both proinflammatory cytokines such as IL-1, IL-6, IL-8, TNF- $\alpha$, and IL-12, and anti-inflammatory cytokines such as IL-10 and TGF- $\beta$ in response to microbial stimuli. The balance of pro- and anti-inflammatory cytokine production is of critical importance to the outcome of an immune response. Understanding this delicate balance is essential to appreciate the complexity of macrophage biology. A large number of studies have been devoted to the dissection of the molecular mechanisms involved in the regulation of proinflammatory cytokine gene expression, which unveiled several important transcription factor families that mediate inflammatory response of macrophages such as NF- $\kappa \mathrm{B}$, NF-IL6, C/EBP, and interferon regulatory factors [89-96]. In contrast, much less is known about the regulation of anti-inflammatory cytokines.

IL-10 gene expression in macrophages is usually triggered by the same typical inflammatory stimuli such as lipopolysaccharides (LPS) that induce the release of proinflammatory cytokines. However, the kinetics of its induction differs from those of the proinflammatory mediators $[63,68,97]$. Recent molecular analyses of the murine IL-10 promoter show that IL-10 transcription in macrophage cell types can be regulated by constitutive and ubiquitous transcription factors such as $\mathrm{Sp} 1$ and $\mathrm{Sp} 3$, suggesting that IL-10 may be produced at low levels constitutively to maintain certain level of control over "baseline" inflammation [98, 99]. Another study provided evidence that post-transcriptional regulation of IL-10 gene expression through sequences in the 3'-untranslated region of the IL-10 mRNA contributes to its overall production as well $[100,101]$. A critical role for Stat 3 but not other Stat proteins in LPS-induced IL-10 transcription in a human 
B cell line was reported by Benkhart and colleagues who demonstrated a direct interaction of Stat 3 with the human IL-10 promoter at -120 [102]. Since Stat3 is also the mediator of IL-10 signaling via the IL-10 receptor [103], this finding provides a mechanistic explanation for the noted autoregulation of IL-10.

\section{IL-10 gene expression during phagocytosis of apop- totic cells}

Our group has carried out studies to elucidate the molecular mechanism whereby apoptotic cells induce the production of IL-10 by phagocytic macrophages. Our preliminary data (unpublished) suggest that:

1) Apoptotic cells induce IL-10 gene transcription and protein production in macrophages.

2) Phagocytosis of apoptotic cells is not required for IL-10 production by macrophages. Cell-cell contact is sufficient. It's partially CD36-dependent.

3) The major apoptotic cell-response element (positive regulator) in the human IL-10 promoter is mapped to $106 /-98$, to which binding with specific nuclear protein(s) is induced by apoptotic cells.

4) A negative element is mapped to $-171 /-129$ where a novel nuclear binding activity has been identified, and this activity is inhibited by contact with apoptotic cells.

5) The p38 mitogen-activated protein kinase (MAPK) is critically involved in apoptotic cell-medicated IL-10 transcription and post-transcriptional regulation.

6) CD36 is essential in the induction of p38 MAPK activation by apoptotic cells.

\section{Conclusion}

Immunoregulatory cytokines IL-10 and IL-12 play important roles in the etiology and pathology of many autoimmune diseases. Elucidation of the apoptotic cell-mediated signaling mechanisms involved in the control of IL-10 and IL-12 production during cell turnovers under normal and pathological conditions may help us counter the cytokine dysregulation and control inappropriate host immune reactions in disorders such as autoimmunity, infectious diseases, graft-versus-host disease, and cancer.

\section{Acknowledgements}

This work was supported by a NIH grant (AI45899) and a grant from the Mary Kirkland Foundation for Lupus Research, both to Xiao Jing Ma.

\section{References}

1 Wyllie AH, Kerr JF Currie AR. Cell death: the significance of apoptosis. Int Rev Cytol 1980; 68:251-306.

2 Savill J, Fadok V, Henson P Haslett C. Phagocyte recognition of cells undergoing apoptosis. Immunol Today 1993; 14:131-6.

3 Albert ML, Pearce SF, Francisco LM, et al. Immature dendritic cells phagocytose apoptotic cells via alphavbeta5 and CD36, and cross-present antigens to cytotoxic T lymphocytes. J Exp Med 1998; 188:1359-68.

4 Fadok VA, Voelker DR, Campbell PA, et al. Exposure of phosphatidylserine on the surface of apoptotic lymphocytes triggers specific recognition and removal by macrophages. J Immunol 1992; 148:2207-16.

5 Verhoven B, Schlegel RA Williamson P. Mechanisms of phosphatidylserine exposure, a phagocyte recognition signal, on apoptotic T lymphocytes. J Exp Med 1995; 182:1597-601.

6 Frasch SC, Henson PM, Kailey JM, et al. Regulation of phospholipid scramblase activity during apoptosis and cell activation by protein kinase Cdelta. J Biol Chem 2000; 275:23065-73.

7 Hoffmann PR, deCathelineau AM, Ogden CA, et al. Phosphatidylserine (PS) induces PS receptor-mediated macropinocytosis and promotes clearance of apoptotic cells. J Cell Biol 2001; 155:649-59.

8 Savill J Fadok V. Corpse clearance defines the meaning of cell death. Nature 2000; 407:784-8.

9 Fadok VA, Bratton DL, Rose DM, et al. A receptor for phosphatidylserine-specific clearance of apoptotic cells. Nature 2000; 405:85-90.

10 Henson PM, Bratton DL Fadok VA. Apoptotic cell removal. Curr Biol 2001; 11:R795-805.

11 Williamson P Schlegel RA. Hide and seek: the secret identity of the phosphatidylserine receptor. J Biol 2004; 3:14.

12 Somersan S Bhardwaj N. Tethering and tickling: a new role for the phosphatidylserine receptor. J Cell Biol 2001; 155:501-4.

13 Grigg JM, Savill JS, Sarraf C, et al. Neutrophil apoptosis and clearance from neonatal lungs. Lancet 1991; 338:720-2.

14 Haslett C, Savill JS, Whyte MK, et al. Granulocyte apoptosis and the control of inflammation. Philos Trans R Soc Lond B Biol Sci 1994; 345:327-33.

15 Cox G, Crossley J, Xing Z. Macrophage engulfment of apoptotic neutrophils contributes to the resolution of acute pulmonary inflammation in vivo. Am J Respir Cell Mol Biol 1995; 12:2327.

16 Voll RE, Roth EA, Girkontaite I, et al. Histone-specific Th0 and Th1 clones derived from systemic lupus erythematosus patients induce double-stranded DNA antibody production. Arthritis Rheum 1997; 40:2162-71.

17 Fadok VA, Bratton DL, Konowal A, et al. Macrophages that have ingested apoptotic cells in vitro inhibit proinflammatory cytokine production through autocrine/paracrine mechanisms involving TGF-beta, PGE2, and PAF. J Clin Invest 1998; 101:890-8.

18 Sun EW Shi YF. Apoptosis: the quiet death silences the immune system. Pharmacol Ther 2001; 92:135-45.

19 Herrmann M, Voll RE, Zoller OM et al. Impaired phagocytosis of apoptotic cell material by monocyte-derived macrophages from patients with systemic lupus erythematosus. Arthritis Rheum 1998; 41:1241-50.

20 Baumann I, Kolowos W, Voll RE, et al. Impaired uptake of apoptotic cells into tingible body macrophages in germinal centers of patients with systemic lupus erythematosus. Arthritis Rheum 2002; 46:191-201. 
21 Perniok A, Wedekind F, Herrmann M, et al. High levels of circulating early apoptic peripheral blood mononuclear cells in systemic lupus erythematosus. Lupus 1998; 7:113-8.

22 Raptis L Menard HA. Quantitation and characterization of plasma DNA in normals and patients with systemic lupus erythematosus. J Clin Invest 1980; 66:1391-9.

23 McCoubrey-Hoyer A, Okarma TB Holman HR. Partial purification and characterization of plasma DNA and its relation to disease activity in systemic lupus erythematosus. Am J Med 1984; 77:23-34.

24 Steinman CR. Circulating DNA in systemic lupus erythematosus. Isolation and characterization. J Clin Invest 1984; 73:832-41.

25 Trinchieri G. Interleukin-12: a proinflammatory cytokine with immunoregulatory functions that bridge innate resistance and antigen-specific adaptive immunity. Annu Rev Immunol 1995; 13:251-76.

26 Oppmann B, Lesley R, Blom B, et al. Novel p19 protein engages IL-12p40 to form a cytokine, IL-23, with biological activities similar as well as distinct from IL-12. Immunity 2000; 13:71525.

27 Trembleau S, Germann T, Gately MK Adorini L. The role of IL-12 in the induction of organ-specific autoimmune diseases. Immunol Today 1995; 16:383-6.

28 Caspi RR. IL-12 in autoimmunity. Clin Immunol Immunopathol 1998; 88:4-13.

29 Trembleau S, Penna G, Bosi E, et al. Interleukin 12 administration induces T helper type 1 cells and accelerates autoimmune diabetes in NOD mice. J Exp Med 1995; 181:817-21.

30 Leonard JP, Waldburger KE, Schaub RG, et al. Regulation of the inflammatory response in animal models of multiple sclerosis by interleukin-12. Crit Rev Immunol 1997; 17:545-53.

31 Rothe H, O'Hara RM, Jr., Martin S Kolb H. Suppression of cyclophosphamide induced diabetes development and pancreatic Th1 reactivity in NOD mice treated with the interleukin (IL)- 12 antagonist IL-12(p40)2. Diabetologia 1997; 40:641-6.

32 Trembleau S, Penna G, Gregori S, et al. Deviation of pancreasinfiltrating cells to Th2 by interleukin-12 antagonist administration inhibits autoimmune diabetes. Eur J Immunol 1997; 27:2330-9.

33 Leonard JP, Waldburger KE Goldman SJ. Prevention of experimental autoimmune encephalomyelitis by antibodies against interleukin 12. J Exp Med 1995; 181:381-6.

34 Constantinescu CS, Wysocka M, Hilliard B, et al. Antibodies against IL-12 prevent superantigen-induced and spontaneous relapses of experimental autoimmune encephalomyelitis. J Immunol 1998; 161:5097-104.

35 Yokoi H, Kato K, Kezuka T, et al. Prevention of experimental autoimmune uveoretinitis by monoclonal antibody to interleukin12. Eur J Immunol 1997; 27:641-6.

36 Tarrant TK, Silver PB, Chan CC, et al. Endogenous IL-12 is required for induction and expression of experimental autoimmune uveitis. J Immunol 1998; 161:122-7.

37 McIntyre KW, Shuster DJ, Gillooly KM, et al. Reduced incidence and severity of collagen-induced arthritis in interleukin-12-deficient mice. Eur J Immunol 1996; 26:2933-8.

38 Liu J Beller D. Aberrant production of IL-12 by macrophages from several autoimmune-prone mouse strains is characterized by intrinsic and unique patterns of NF-kappa B expression and binding to the IL-12 p40 promoter. J Immunol 2002; 169:581-6.

39 Simpson PB, Mistry MS, Maki RA, et al. Cuttine edge: diabetes- associated quantitative trait locus, Idd4, is responsible for the IL-12p40 overexpression defect in nonobese diabetic (NOD) mice. J Immunol 2003; 171:3333-7.

40 Segal R, Dayan M, Zinger H, et al. The effect of IL-12 on clinical and laboratory aspects of experimental SLE in young and aging mice. Exp Gerontol 2003; 38:661-8.

41 Wong CK, Ho CY, Li EK Lam CW. Elevation of proinflammatory cytokine (IL-18, IL-17, IL-12) and Th2 cytokine (IL-4) concentrations in patients with systemic lupus erythematosus. Lupus 2000; 9:589-93.

42 Robak E, Robak T, Wozniacka A, et al. Proinflammatory interferon-gamma--inducing monokines (interleukin-12, interleukin18, interleukin-15)--serum profile in patients with systemic lupus erythematosus. Eur Cytokine Netw 2002; 13:364-8.

43 Lauwerys BR, Van Snick J Houssiau FA. Serum IL-12 in systemic lupus erythematosus: absence of $\mathrm{p} 70$ heterodimers but presence of p40 monomers correlating with disease activity. Lupus 2002; 11:384-7.

44 Spadaro A, Scrivo R, Rinaldi T, et al. The role of interleukin-12 in immune-mediated rheumatic diseases. Reumatismo 2002; 54:113-21.

45 Li Z, Li Y, Huang L, et al. Expression of interleukin-12 and its signaling molecules in peripheral blood mononuclear cells in systemic lupus erythematosus patients. Chin Med J (Engl) 2002; 115:846-50.

46 Filatenkov AA, Jacovetty EL, Fischer UB, et al. CD4 T CellDependent Conditioning of Dendritic Cells to Produce IL-12 Results in CD8-Mediated Graft Rejection and Avoidance of Tolerance. J Immunol 2005; 174:6909-17.

47 Eaton AD, Xu D, Garside P. Administration of exogenous interleukin-18 and interleukin-12 prevents the induction of oral tolerance. Immunology 2003; 108:196-203.

48 Pflanz S, Timans JC, Cheung J, et al. IL-27, a heterodimeric cytokine composed of EBI3 and p28 protein, induces proliferation of naive CD4(+) T cells. Immunity 2002; 16:779-90.

49 Chen Q, Ghilardi N, Wang H, et al. Development of Th1-type immune responses requires the type I cytokine receptor TCCR. Nature 2000; 407:916-20.

50 Yoshida H, Hamano S, Senaldi G, et al. WSX-1 is required for the initiation of Th1 responses and resistance to L. major infection. Immunity 2001; 15:569-78.

51 Salcedo R, Stauffer JK, Lincoln E, et al. IL-27 mediates complete regression of orthotopic primary and metastatic murine neuroblastoma tumors: role for CD8+ T cells. J Immunol 2004; 173:7170-82.

52 Chiyo M, Shimozato O, Yu L, et al. Expression of IL-27 in murine carcinoma cells produces antitumor effects and induces protective immunity in inoculated host animals. Int J Cancer 2005; 115:437-42.

53 Li J, Gran B, Zhang GX, et al. IL-27 subunits and its receptor (WSX-1) mRNAs are markedly up-regulated in inflammatory cells in the CNS during experimental autoimmune encephalomyelitis. J Neurol Sci 2005; 232:3-9.

54 Goldberg R, Zohar Y, Wildbaum G, et al. Suppression of ongoing experimental autoimmune encephalomyelitis by neutralizing the function of the p28 subunit of IL-27. J Immunol 2004; 173:646571.

55 Kim S, Elkon KB, Ma X. Transcriptional Suppression of Interleukin-12 Gene Expression following Phagocytosis of Apoptotic 
Cells. Immunity 2004; 21:643-53.

56 Kim S, Chung EY, Ma X. Immunological Consequences of Macrophage-mediated Clearance of Apoptotic Cells. Cell Cycle 2005; 4:231-4.

57 Burke PS, Don J, Wolgemuth DJ. Zfp-51, a murine zinc finger encoding gene mapping to the t-complex region of chromosome 17 , encodes 19 contiguous zinc fingers and is ubiquitously expressed. Mamm Genome 1994; 5:387-9.

58 Vanden Heuvel JP, Holden P, Tugwood J, et al. Identification of a novel peroxisome proliferator responsive cDNA isolated from rat hepatocytes as the zinc-finger protein ZFP-37. Toxicol Appl Pharmacol 1998; 152:107-18.

59 Castrillo A, Tontonoz P. Nuclear receptors in macrophage biology: at the crossroads of lipid metabolism and inflammation. Annu Rev Cell Dev Biol 2004; 20:455-80.

60 Natarajan C, Bright JJ. Peroxisome proliferator-activated receptor-gamma agonists inhibit experimental allergic encephalomyelitis by blocking IL-12 production, IL-12 signaling and Th1 differentiation. Genes Immun 2002; 3:59-70.

61 Kim S, Chung EY, Ma X. Immunological consequences of macrophage-mediated clearance of apoptotic cells. Cell Cycle 2005; 4:231-4.

62 Moore KW, Vieira P, Fiorentino DF, et al. Homology of cytokine synthesis inhibitory factor (IL-10) to the Epstein- Barr virus gene BCRFI. Science 1990; 248:1230-4.

63 de Waal Malefyt R, Haanen J, Spits H, et al. Interleukin 10 (IL10) and viral IL-10 strongly reduce antigen-specific human $T$ cell proliferation by diminishing the antigen-presenting capacity of monocytes via downregulation of class II major histocompatibility complex expression. J Exp Med 1991; 174:915-24.

64 Fiorentino DF, Zlotnik A, Vieira P, et al. IL-10 acts on the antigen-presenting cell to inhibit cytokine production by Th1 cells. J Immunol 1991; 146:3444-51.

65 Ding L, Shevach EM. IL-10 inhibits mitogen-induced T cell proliferation by selectively inhibiting macrophage costimulatory function. J Immunol 1992; 148:3133-9.

66 Hsu DH, Moore KW, Spits H. Differential effects of IL-4 and IL-10 on IL-2-induced IFN-gamma synthesis and lymphokineactivated killer activity. Int Immunol 1992; 4:563-9.

67 Bogdan C, Vodovotz Y, Nathan C. Macrophage deactivation by interleukin 10. J Exp Med 1991; 174:1549-55.

68 de Waal Malefyt R, Abrams J, Bennett B, et al. Interleukin 10(IL-10) inhibits cytokine synthesis by human monocytes: an autoregulatory role of IL-10 produced by monocytes. J Exp Med 1991; 174:1209-20.

69 Fiorentino DF, Zlotnik A, Mosmann TR, et al. IL-10 inhibits cytokine production by activated macrophages. J Immunol 1991; 147:3815-22.

70 Ding L, Linsley PS, Huang LY, et al. IL-10 inhibits macrophage costimulatory activity by selectively inhibiting the up-regulation of B7 expression. J Immunol 1993; 151:1224-34.

71 Gazzinelli RT, Oswald IP, James SL Sher A. IL-10 inhibits parasite killing and nitrogen oxide production by IFN- gammaactivated macrophages. J Immunol 1992; 148:1792-6.

72 Oswald IP, Gazzinelli RT, Sher A James SL. IL-10 synergizes with IL-4 and transforming growth factor-beta to inhibit macrophage cytotoxic activity. J Immunol 1992; 148:3578-82.

73 Ralph P, Nakoinz I, Sampson-Johannes A, et al. IL-10, T lymphocyte inhibitor of human blood cell production of IL-1 and tumor necrosis factor. J Immunol 1992; 148:808-14.

74 Murphy EE, Terres G, Macatonia SE, et al. B7 and interleukin 12 cooperate for proliferation and interferon gamma production by mouse Thelper clones that are unresponsive to B7 costimulation. J Exp Med 1994; 180:223-31.

75 Kuhn R, Lohler J, Rennick D, et al. Interleukin-10-deficient mice develop chronic enterocolitis. Cell 1993; 75:263-74.

76 Berg DJ, Leach MW, Kuhn R, et al. Interleukin 10 but not interleukin 4 is a natural suppressant of cutaneous inflammatory responses. J Exp Med 1995; 182:99-108.

77 Berg DJ, Kuhn R, Rajewsky K, et al. Interleukin-10 is a central regulator of the response to LPS in murine models of endotoxic shock and the Shwartzman reaction but not endotoxin tolerance. J Clin Invest 1995; 96:2339-47.

78 Bettelli E, Das MP, Howard ED, et al. IL-10 is critical in the regulation of autoimmune encephalomyelitis as demonstrated by studies of IL-10- and IL-4-deficient and transgenic mice. J Immunol 1998; 161:3299-306.

79 Fuss IJ, Boirivant M, Lacy B Strober W. The interrelated roles of TGF-beta and IL-10 in the regulation of experimental colitis. J Immunol 2002; 168:900-8.

80 Oberholzer A, Oberholzer C, Moldawer LL. Interleukin-10: A complex role in the pathogenesis of sepsis syndromes and its potential as an anti-inflammatory drug. Crit Care Med 2002; 30: S58-S63.

81 Conti P, Kempuraj D, Kandere K, et al. IL-10, an inflammatory/inhibitory cytokine, but not always. Immunol Lett 2003; 86:123-9.

82 Chen WF Zlotnik A. IL-10: a novel cytotoxic T cell differentiation factor. J Immunol 1991; 147:528-34.

83 Groux H, Cottrez F, Rouleau M, et al. A transgenic model to analyze the immunoregulatory role of IL-10 secreted by antigenpresenting cells. J Immunol 1999; 162:1723-9.

84 Takayama T, Tahara H, Thomson AW. Differential effects of myeloid dendritic cells retrovirally transduced to express mammalian or viral interleukin-10 on cytotoxic T lymphocyte and natural killer cell functions and resistance to tumor growth. Transplantation 2001; 71:1334-40.

85 Carson WE, Lindemann MJ, Baiocchi R, et al. The functional characterization of interleukin-10 receptor expression on human natural killer cells. Blood 1995; 85:3577-85.

86 Thompson LM, Rubin RT, McCracken JT. Neuroendocrine aspects of primary endogenous depression: XII. Receiver operating characteristic and kappa analyses of serum and urine cortisol measures in patients and matched controls. Psychoneuroendocrinology 1992; 17:507-15.

87. MacNeil IA, Suda T, Moore KW, et al. IL-10, a novel growth cofactor for mature and immature T cells. J Immunol 1990; 145:4167-73.

88 Groux H, Cottrez F. The complex role of interleukin-10 in autoimmunity. J Autoimmun 2003; 20:281-5.

89 Grove M, Plumb M. C/EBP, NF-kappa B, and c-Ets family members and transcriptional regulation of the cell-specific and inducible macrophage inflammatory protein 1 alpha immediateearly gene. Mol Cell Biol 1993; 13:5276-89.

90 Matsusaka T, Fujikawa K, Nishio Y, et al. Transcription factors NF-IL6 and NF-kappa B synergistically activate transcription of the inflammatory cytokines, interleukin 6 and interleukin 8 . Proc Natl Acad Sci U S A 1993; 90:10193-7. 
91 Stein B, Baldwin AS Jr. Distinct mechanisms for regulation of the interleukin- 8 gene involve synergism and cooperativity between C/EBP and NF-kappa B. Mol Cell Biol 1993; 13:7191-8.

92 Murphy TL, Cleveland MG, Kulesza P, et al. Regulation of interleukin 12 p40 expression through an NF-kappa B half- site. Mol Cell Biol 1995; 15:5258-67.

93 Ma X, Chow JM, Gri G, et al. The interleukin 12 p40 gene promoter is primed by interferon gamma in monocytic cells. $\mathrm{J}$ Exp Med 1996; 183:147-57.

94 Ma X, Neurath M, Gri G, Trinchieri G. Identification and characterization of a novel Ets-2-related nuclear complex implicated in the activation of the human interleukin- 12 p 40 gene promoter. J Biol Chem 1997; 272:10389-95.

95 Plevy SE, Gemberling JH, Hsu S, et al. Multiple control elements mediate activation of the murine and human interleukin 12 p40 promoters: evidence of functional synergy between C/EBP and Rel proteins. Mol Cell Biol 1997; 17:4572-88.

96 Grazia Cappiello M, Sutterwala FS, Trinchieri G, et al. Suppression of Il-12 transcription in macrophages following Fc gamma receptor ligation. J Immunol 2001; 166:4498-506.

97 Yssel H, De Waal Malefyt R, Roncarolo MG, et al. IL-10 is produced by subsets of human CD4+ T cell clones and peripheral blood T cells. J Immunol 1992; 149:2378-84.

98 Brightbill HD, Plevy SE, Modlin RL, Smale ST. A prominent role for Sp1 during lipopolysaccharide-mediated induction of the IL10 promoter in macrophages. J Immunol 2000; 164:1940-51.

99 Tone M, Powell MJ, Tone Y, et al. IL-10 gene expression is controlled by the transcription factors Sp1 and Sp3. J Immunol 2000; 165:286-91.

100Powell MJ, Thompson SA, Tone Y, et al. Posttranscriptional regulation of IL-10 gene expression through sequences in the 3'-untranslated region. J Immunol 2000; 165:292-6.

101 Brewer G, Saccani S, Sarkar S, et al. Increased interleukin-10 mRNA stability in melanoma cells is associated with decreased levels of A + U-rich element binding factor AUF1. J Interferon Cytokine Res 2003; 23:553-64.

102Benkhart EM, Siedlar M, Wedel A, et al. Role of Stat3 in lipopolysaccharide-induced IL-10 gene expression. J Immunol 2000; 165:1612-7.

103 Moore KW, de Waal Malefyt R, Coffman RL, O'Garra A. Interleukin-10 and the interleukin-10 receptor. Annu Rev Immunol 2001; 19:683-765. 